\title{
NUEVOS DATOS PARA LA COLONIA SALARIA
}

\author{
HELENA GIMENO PASCUAL \\ Centro CIL II (Universidad de Alcalá)
}

\begin{abstract}
Un manuscrito de M. Vázquez Siruela contiene una nueva inscripción romana de Salaria. El texto menciona por primera vez a un flamen local de la ciudad e incluye la mención epigráfica de la colonia Salaria. Al mismo tiempo, documenta la presencia en la ciudad de la tribus Galeria.

A manuscript by M. Vázquez Siruela from the Biblioteca Colombina in Seville includes a new Roman inscription from Salaria. The text makes the first reference to a flamen belonging to the city and includes an epigraphical reference to the colonia Salaria. It also documents the presence of the tribus Galeria amongst the Roman citizens of this community.
\end{abstract}

No dejan de producir sorpresas para la epigrafía hispana los manuscritos del canónigo granadino M. Vázquez Siruela ${ }^{1}$. En uno de ellos conservado en la biblioteca Capitular y Colombina de Sevilla ${ }^{2}$ se encuentra el dibujo y trascripción de un epígrafe inédito hallado en "S. Olalla media legua de Úbeda entre Oriente i Norte... en unas hazas un tiro de arcabuz del lugar". Al pie del dibujo indica Siruela manu propria exscripsi el día 23 de Noviembre del año 1639 , aunque también señala que se había hallado seis años antes o sea, en torno a 1633. Este lugar de Santa Olalla, con lo único que parece poder identificarse es con la ermita de Santa Eulalia ${ }^{3}$, situada a unos $4 \mathrm{~km}$ al Noroeste de Úbeda, que precisamente ha dado nombre a la aldea de Santa Eulalia, en cuyos alrededores se encuentra el "cortijo de Calatrava", conocido popularmente por "Las Ruinas", que no sabemos si coincidiría con el lugar donde se hallaban "los vestigios de antigüedad que cada día descubren los labradores", que menciona el manuscrito. Los datos, sin embargo, no coinciden con la situación que da Siruela de Santa Olalla al Noreste y a media legua de Úbeda, quizá debamos considerar que Siruela escribió Oriente por Occidente y que no calculara bien la distancia.

El dibujo representa un pedestal con coronamiento y base (Fig. 1). Era una "columna quadrada" de "piedra franca" -probablemente la caliza clara en la que se elaboraron la mayoría de las inscripciones de Úbeda-, "de casi seis palmos de altura, dos de ancho i dos $i$ medio de grueso" es decir, unos $126 \times 42 \times 52$ $\mathrm{cm}$. Según el dibujo la letra sería libraria.

$D($ is $) \cdot M($ anibus $) \cdot s($ acrum $)$
$M($ arcus $) \cdot$ lulius $M($ arci $) \cdot f(i l i u s)$
Galeria Aemili-
anus col(onia) Salar(ia)
IIvir bis flam-
en Romae et Aug(ust-)
annor(um) XXXXV
[pi]us in suis $\cdot h(i c)$ s(itus) e-
st s(it) t(ibi) ter(ra) levis
[A]elia Secundina
uxor posuit

Hay varios aspectos interesantes a destacar en esta inscripción. El primero es que se trata del primer flamen local atestiguado en

\footnotetext{
* Este trabajo se presenta como uno de los resultados del Proyecto de Investigación CAM 06/0103/02. Agradezco a J. Delgado Delgado y a A. U. Stylow sus sugerencias y consejos.

1 Sobre su labor epigráfica véase Gimeno Pascual y Stylow, 1998, 89-156. Descalifica, injustamente, su pericia Ballesteros (2002, 141-170) sin llevar a cabo un estudio minucioso de la traditio de cada inscripción que comenta asi como por desconocimiento de la obra epigráfica de Siruela en su conjunto.

2 Biblioteca Capitular y Colombina ms. 60-1-13, f. 211. Agradecemos a esta institución las facilidades que nos ha dado para la utilización de sus fondos.
}

${ }^{3}$ A una legua al NO de Úbeda según Madoz (1849, XV, 195). 


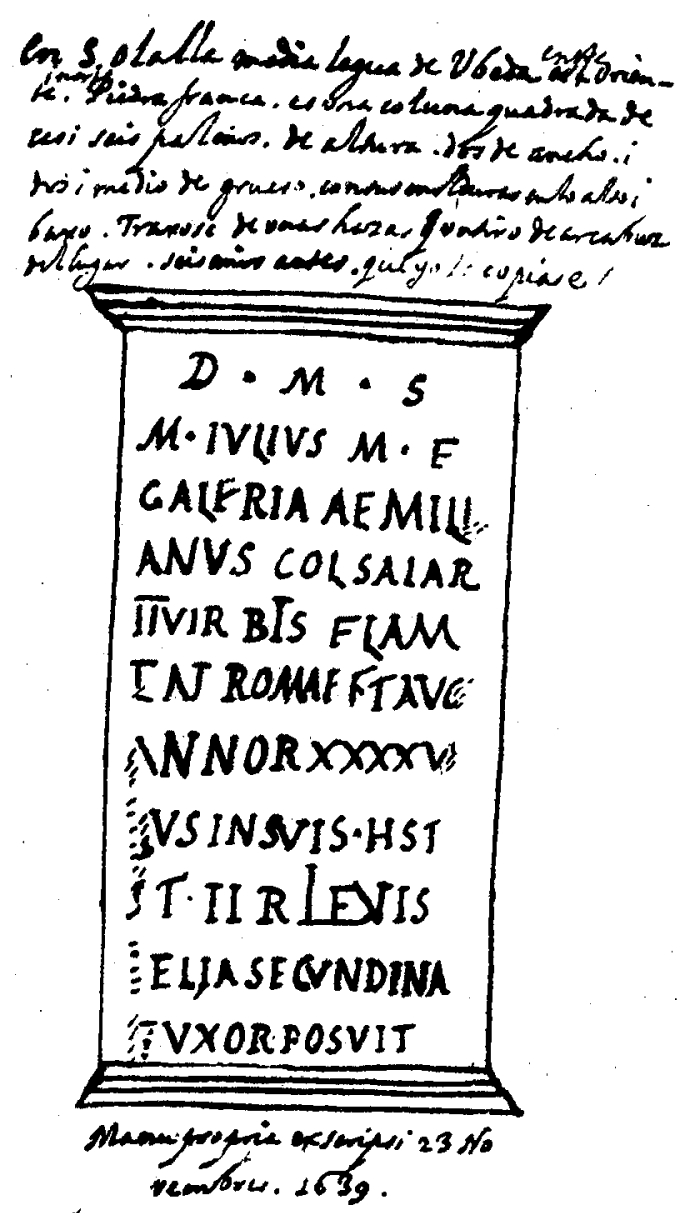

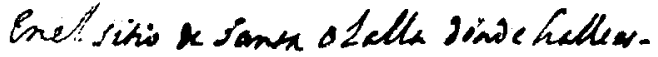

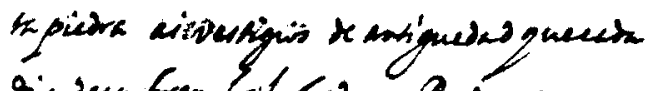

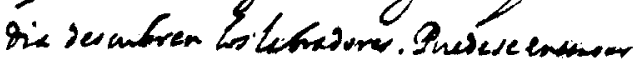

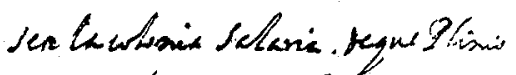

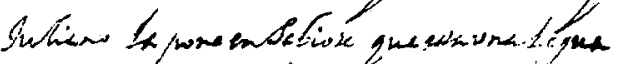

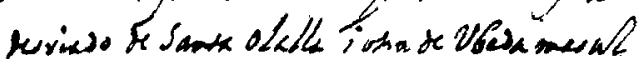

onive.

Figura 1: Dibujo procedente de la Institución Colombina, Biblioteca Capitular de Sevilla.

la colonia Salaria 4 . Como el resto de sacerdotes de las colonias y municipios de Hispania es un ingenuus (vid. Delgado Delgado, 1998, 142; Delgado Delgado, 2003, 224-225), que disfruta de la condición de civis Romanus. También las circunstancias de su cursus son frecuentes en ese grupo de la élite local: ejerció dos veces, como única magistratura, el duovirato en la colonia y obtuvo el flaminado. Así M. Iulius Aemilianus no se promocionó más allá de su propia comunidad, situación que se produce con frecuencia entre los flámines municipales hispanos ya que no fueron muchos los que accedieron al equester ordo, aunque el porcentaje varia en función de las provincias ${ }^{5}$. Su sacerdocio flamen Romae et Augusti encaja perfectamente en la Hispania Citerior ${ }^{6}$ donde, a diferencia de la Bética y Lusitania ${ }^{7}$, es habitual

4 Mencionada por Plinio (nat. 3, 25) entre los sesenta y cinco populi del conventus Carthaginiensis (Carthaginem conveniunt populi $L X V$ exceptis insularum incolis ex colonia Accitania Gemellense, ex Libisosana cognomine Foroaugustana, quibus duabus ius Italiae datum, ex colonia Salariense...) y por Ptolemeo (II 6, 58. II, 6, 60) primero como ciudad de la Oretania y a continuación situándola en la Bastetania (cf. Tovar, 1989, $167 \mathrm{C}-41$ y $183 \mathrm{C}-65$ ) se identifica con la actual úbeda la Vieja $15 \mathrm{~km}$ al Sureste de Úbeda. En sus ruinas se encontró un pedestal (CIL || $5093=$ CILAJaén 357) dedicado por los coloni probablemente a uno de los hijos de Augusto como patrono de la colonia (cf. Abascal, 1996, 65-66), así como el epitafio de una Salariensis (CILAJaèn 364).

${ }^{5}$ Cf. Étienne, 1958, 230 y las tablas en 225-229, aunque ya están desfasadas. Para la Bética y Lusitania contamos ya con los trabajos de Delgado Delgado, 1998, 67 y 2000: 117 ss. Mientras que en la Bética son muy escasos, en la Lusitania no parece haber sido un hecho excepcional como ha comprobado Delgado (2000, 120).

${ }^{6}$ Por mencionar algunos ejemplos: en Barcino (CIL II 4520 $=$ IRC IV 50. CIL || $4516=$ CIL || $6147=$ IRC IV 42 y CIL II $4514=$ IRC IV 45, que también incluye a los Divi), Castulo (CIL II 3276 = CILAJaén 97; CILAJaén 98?, CILAJaén 99100), Clunia (ERCLU 18, CIL II 2782 = ERCLU 28), Complutum (CIL II 3033), Dertosa (CIL II²/14, 792-793), Emporion (IRC III 44), lesso (CIL II 4610 = IRC I 141), I/uro (IRC I 102), Pollentia (CIL II 3696), Saetabis (CIL II 3623), Tarraco (CIL || $4224=$ RIT 171. CIL || $6097=$ RIT 173), Valeria (CIL II 3179). También sacerdotes locales, pero no sabemos en qué se diferenciaba su función de la de los flamines, podían ser algunos sacerdotes Romae et Augusti: así dos individuos cuyas inscripciones se hallaron en Asturica Augusta (CIL II 5124 y CIL II 2638 = Mañanes 2000: 23-24); uno de ellos estaba designado para flamen de la provincia, el otro sacerdos ad Lucum Augusti fue flamen provincial y tribuno de la legión I Itálica. En Tarraco a un sacerdos Romae et Aug(usti) de Bergidum Flavium le fue concedida una estatua entre los viri flaminales (CIL II $4248=$ RIT 333). Otros sacerdotes superaban el ámbito estrictamente local como un sacerdos Romae et Aug(usti) Ar(arum) Augustanarum, también de un pedestal de Tarragona, que fue después flamen provincial (CIL II $6093=$ RIT 256) o Ti. Claudius Pressus quaestor gentium Araugustanor(um) y dilectator del emperador Galba (Eck, W., 1997, 200-207) asi como los sacerdotes del conventus Asturum CIL I| 6094 = RIT 275 y CIL \| $4223=$ RIT 287.

$7 \mathrm{Ni}$ en Lusitania ni en la Bética aparece una sola mención específica de flámines locales o provinciales vinculados al culto de Roma (cf. su ausencia en Delgado, 1999, 2000 y 2001). Según Étienne $(1958,163)$, desde Vespasiano, son los mismos flamines Aug(usti) los que se ocupan de dicho culto; aunque hay que tener en cuenta que, en la Bética, la mayoria de las veces en las inscripciones de flámines no constan los títulos específicos de los sacerdocios (cf. Delgado, 1998, 50 y 68 tabla III. 12). Llama la atención que, en Hispania, la distribución geográfica de los sacerdocios asociados a Roma se concentra en las zonas de más débil romanización. 
que los flámines locales lo especifiquen junto al cargo ${ }^{8}$.

En este pedestal, además, aparece la segunda mención epigráfica de la colonia Salaria, esta vez en una inscripción procedente del territorio de la propia colonia puesto que, hasta ahora, sólo aparecía como lugar de ejercicio del cargo de un duóviro en una inscripción de la cercana Tugia (Toya, Peal del Becerro, Jaén) sobre la que volveremos después ${ }^{9}$. Como se trata de un epígrafe funerario que fue hallado a "un tiro de arcabuz", es decir a unos 25 o $30 \mathrm{~m}$ de la ermita, hay que descartar que hubiera sido trasladado para su reutilización desde una necrópolis urbana; más bien estuvo en alguna propiedad fundiaria de la familia del difunto, alguna de las muchas villae del ager de la colonia (cf. CILAJaén p. 400) a la que pudieran corresponder los vestigios antiguos que, según Siruela, los labradores descubrían en el sitio de Santa Olalla ${ }^{10}$.

En tercer lugar, documenta en Salaria la tribus Galeria, donde conociamos ya la Sergia gracias, por un lado, a la inscripción del duóviro ya mencionado de Toya ${ }^{11}$, que no puede atribuirse a Tugia porque los ciudadanos de ese municipio flavio no estuvieron adscritos a la Sergia como ya argumentó Wiegels (1985, 133), y a otra inscripción funeraria que se fecha en la segunda mitad del s. I a. $\mathrm{C}^{12}$. Con este nuevo testimonio la colonia Salaria desaparece de la lista de ciudades de las que sólo se conocía la tribus Sergia para engrosar la más numerosa de aquéllas en las que coexisten ambas tribus (vid. Stylow, 1993, 81 ss.; Stylow, 1995,116 ss.) y que cada vez se manifiesta más como una situación habitual en las colonias hispanas (Stylow, 1995, 117). No sabemos, a falta de epítetos en el caso de la colonia Salaria, si su doble tribus pudo haber correspondido o no a un dúplice asentamiento, como se ha propuesto en el caso de algunas colonias como Corduba (cf. Stylow, 1993, 81; Stylow, 1995, 121), Tucci, Urso, o Hispalis (Stylow, 1995, 117). Si bien con la tribus de M. Iulius Aemilianus no encontramos el argumento definitivo para confirmar la fundación augústea de Salaria defendida por algunos investigadores ${ }^{13}$ solo por el hecho de haberse encontrado el homenaje de los colonos a uno de los hijos adoptivos de Augusto ${ }^{14}$ como patrono de la colonia, sí al menos puede ser considerada como sorteable entre las colonias que hubieran recibido una segunda deductio por parte de dicho emperador. Pero ello no impide descartar que en Salaria hubieran coexistido ambas tribus desde su fundación.

Por último en sentido estrictamente epigráfico también es interesante constatar que, como otras inscripciones de Salaria (CILAJaén $358,363-364,366$ ), incluye el típico formulario bético pius in suis, prueba de su afinidad con la Bética, de la que había formado parte hasta el 11 a. C., en las fórmulas y otros hábitos epigráficos (cf. Stylow, 2002, 354). Precisamente por el formulario fechariamos la inscripción a finales del siglo II o en el III aunque no con posterioridad a época severiana.
Helena Gimeno Pascual
Centro CIL II-España, Universidad de Alcalá
PI. de San Diego s/n
28801 Alcalá de Henares

\begin{abstract}
${ }^{8}$ Sobre el culto a Roma y los flámines locâles y provinciales, estos últimos asociados a él, especialmente, a partir de Vespasiano vid. Étienne, 1958, 163. 235. 293. 454-455.
\end{abstract}

9 Se trata de CIL II 3329 = CILAJaén 542. Este duoviro fue también flamen Augustorum provincial y su mujer flaminica de la provincia Hispania Citerior; según Alföldy (1973, 86 n. 58) ejercería su cargo entre los años 70 y 90 . Cf. el texto infra nota 11. Salariensis como origo de una liberta, se menciona en un epígrafe encontrado en la misma Úbeda la Vieja (CILAJaén 364).

10 La aparición de esta inscripción con la mención de un duoviro de la colonia Salaria, unida a esa abundancia de restos arqueológicos ya le hizo sospechar a Siruela que pudiera tratarse de la colonia Salaria que Plinio mencionaba, aunque no le cuadraba con lo que decía Juliano, uno de los autores de los falsos cronicones, que ubicaba Salaria en Sabiote, localidad que se sitúa "a una legua desviado de santa Olalla i otra de Ubeda más al Oriente". Para las distintas localizaciones de Salaria en la tradición anticuaria del siglo XVII vid. Antonio $(1742,234)$, quien indica, sin más datos, la existencia de una inscripción -que no hemos podidos identificar-en la que se mencionaba una colonia lulia Salariense. Por ello y hasta que no se produzca la confirmación de la misma preferimos no hacer uso de este testimonio.

${ }^{11}$ CIL $\| 3329$ = CILAJaén 542. L(ucius) Post[u]mius Q(uinti) f(ilius) Serg(ia) Fabul[lus? fl]a[men] / August[o]rum provinc(iae) Hi[spaniae cit(erioris) tri]b(unus) m[i]l(itum) /leg(ionis) VII Ilvir coloniae Sa[l]ariae et / Manlia L(uci) f(ilia) Silana flaminica / eiusdem provinc(iae) d(ederunt) [d(edicaverunt)].

12 Fechada por González y Mangas en época julio-claudia (CILAJaén 365); lectura y cronología corregida por A. U. Stylow (1993, 85 nota 57). Beltrán y Baena $(1996,38,148)$, que llevan a cabo un concienzudo estudio y ensayan en él una reconstrucción del monumento funerario en el que se encontraba el sillar inscrito, proponen un marco cronológico desde Augusto a mediados del siglo I d. C.

13 Así p. ej. Galsterer, 1971, 27 y 71 n. 64; cf. González, $1989,145-146$, con las distintas propuestas sobre la fundación augústea que, según él, carecía de datos objetivos en que apoyarse.

14 Cf. supra nota 4. González loc. cit. por la ausencia de cognomen no excluye que la colonia pudiera haber sido fundada en una época anterior. 


\section{BIBLIOGRAFÍA}

ABASCAL, J. M., 1996: "Programas epigráficos augústeos en Hispania", Anales de Arqueologia Cordobesa, 7, 4582.

ALFÖLDY, G., 1973: Flamines provinciae Hispaniae Citerioris, Anejos de "Archivo Español de Arqueología" 6, Madrid.

ANTONIO, Nicolás, 1742: Censura de Historias fabulosas, ed. G. Mayans i Siscar, Valencia.

BALLESTEROS, J. R., 2002: La antigüedad barroca. Libros, inscripciones y disparates en el entorno del III marqués de Estepa, Estepa.

BELTRÁN FORTES, J. y BAENA DEL ALCÁZAR, L., 1996: Arquitectura funeraria de la Colonia Salaria (Úbeda, Jaén). Ensayo de sistematización de los monumenta funerarios del Alto Guadalquivir, Sevilia.

CILAJaén: GONZÁLEZ ROMÁN, C. y MANGAS MANJARRÉS, J., 1991: Corpus de inscripciones latinas de Andalucia, vol. III, Jaén, Sevilla.

DELGADO DELGADO, J. A., 1998: Élites y organización de la religión en las provincias romanas de la Bética y las Mauritanias: sacerdotes y sacerdocios, BAR S724, Oxford.

DELGADO DELGADO, J. A., 1999: "Flamines provinciae Lusitaniae", Gerión, 17, 433-461.

DELGADO DELGADO, J. A., 2000: "Los sacerdotes de rango local de Lusitania", Conimbriga, 39, 107-152.

DELGADO DELGADO, J. A.; 2001: "Los fasti sacerdotum de las ciudades de la Bética", Habis, 32, 297-332.

DELGADO DELGADO, J. A., 2003: "Los sacerdotes en el marco de las instituciones municipales en la Hispania Romana", en: Les élites et leurs facettes. Les élites locales dans le monde hellénistique et romain (textes réunis par M. Cébeillac-Gervasoni et L. Lamoine), 223-240, Rome-Clermont-Ferrand.
ÉTIENNE, R., 1958: Le culte imperial dans la Péninsule Ibérique, d'Auguste a Diocletien, París.

ECK, W., 1997: «Fünf Ehreninschriften auf Bronze aus Spanien», Chiron, 27, 200-207.

ERCLU: PALOL, P. de, y VILELLA, J., 1987: Clunia 1/. La epigrafía de Clunia, EAE 150, Madrid.

GALSTERER, H., 1971: Untersuchungen zum römischen Städtewesen auf der iberischen Halbinsel, Berlin.

GIMENO PASCUAL, H. y STYLOW, A. U., 1998: "Intelectuales del siglo XVII: sus aportaciones a la epigrafía de la Bética", Polis, 10, 89-156.

GONZÁLEZ, J.: 1989: Estudios sobre Urso, Sevilla.

MADOZ, P., 1848-1850: Diccionario Geográfico, Estadistico, Histórico de España y sus posesiones de ultramar, Madrid.

MAÑANES, T. 2000: Inscripciones latinas de Astorga, Valladolid

IRC: FABRE, G., MAYER, M. y RODẢ, I., 1984-1997: Inscriptions romaines de Catalogne: I Barcelone (sauf Barcino), 1984; // Lérida, 1985; /II Gérone, 1991; IV Barcino, 1997, Paris

RIT: ALFÖLDY, G., 1975: Die römischen Inschriften von Tarraco, Madrider Forschungen 10, Berlin.

STYLOW, A. U., 1993: "De Corduba a Colonia Patricia. La fundación de la Corduba Romana", Colonia Patricia Corduba. Una reflexión arqueológica, coloquio internacional, 77-85, Córdoba.

STYLOW, A. U., 1995: "Apuntes sobre las tribus romanas en Hispania", Veleia, 12, 105-123.

STYLOW, A. U., 2002: "La epigrafía funeraria en la Bética", en Vaquerizo, D. (ed): Espacios y Usos Funerarios en el Occidente Romano, 353-368, Córdoba.

TOVAR, A., 1989: Iberische Landeskunde. Segunda parte. Tomo 3 Tarraconensis, Baden-Baden.

WIEGELS, R. 1985: Die Tribusinschriften des römisches Hispanien, Berlín. 